\title{
Utilities and placement skills of the incision protective sleeve in video-assisted thoracoscopic surgery (VATS)
}

\author{
Zhiyong Su ${ }^{1 \#}$, Chao Wu ${ }^{2 \#}$, Hongliang Bian ${ }^{1}$, Zhiqiang Zhou ${ }^{1}$, Tianshuo Jiang ${ }^{1}, \mathrm{Xin}_{\mathrm{Zhao}}{ }^{1}$, Fangchao Liu ${ }^{1}$, \\ Yilei Zhang', Keli Lin ${ }^{1}$, Qingshan Gao ${ }^{1}$ \\ ${ }^{1}$ Department of Thoracic Surgery, Chifeng University Affiliated Hospital, Chifeng, China; ${ }^{2}$ Department of Obstetrics and Gynecology, Chifeng \\ University Affiliated Hospital, Chifeng, China \\ Contributions: (I) Conception and design: Z Su, C Wu; (II) Administrative support: Z Su; (III) Provision of study materials or patients: T Jiang, H \\ Bian; (IV) Collection and assembly of data: X Zhao, F Liu, Y Zhang, K Lin, Q Gao; (V) Data analysis and interpretation: T Jiang, H Bian; (VI) \\ Manuscript writing: All authors; (VII) Final approval of manuscript: All authors. \\ \#These authors contributed equally to this work. \\ Correspondence to: Zhiyong Su. Department of Thoracic Surgery, Chifeng University Affiliated Hospital, Songshan District, Chifeng 024001, China. \\ Email: suzhiyong1967@126.com.
}

Background: The incision protective sleeve can protect incisions and help to establish an operating port and thus has been widely applied in thoracic surgeries. However, its other utilities are often neglected. This article explores the additional functions and placement techniques of incision protective sleeves in videoassisted transthoracic surgery (VATS).

Methods: Operators with different surgical experience were divided into three groups: resident group, attending surgeon group, and professor group. Each group independently chose one of the four surgical maneuvers, and the incision protective sleeve was placed during the operation. Up to 200 operations were randomly selected in each group, and the patients' gender, age, incision site, incision length, the operator's experience, and the time and technique of incision protective sleeve placement were recorded. CT was performed to measure the thickness of chest wall and the width of intercostal spaces. Data were analyzed using SPSS 21.0 software package. Multivariate linear regression analysis was performed was performed for the time required for incision protective sleeve placement.

Results: The operator's experience was inversely related to the time required for incision protective sleeve placement, width of intercostal spaces was negatively correlated with operative time, chest wall thickness and incision length were positively correlated with operative time. Among the maneuvers, incision protective sleeve placement skills were significant different.

Conclusions: The placement of the incision protective sleeve for VATS is affected by multiple factors, which are not only related to the patient's condition, chest wall thickness and intercostal space, but also closely related to the operator's experience and the manipulation adopted.

Keywords: Incision protective sleeve; utilities; placement skills

Submitted Feb 26, 2020. Accepted for publication Dec 02, 2020.

doi: $10.21037 /$ jtd-20-2703

View this article at: http://dx.doi.org/10.21037/jtd-20-2703

\section{Introduction}

Since the introduction of VATs in thoracic surgery in the 1990s, after more than 20 years of development, it has been widely used in the diagnosis and treatment of chest diseases. With the update of minimally invasive surgery concept and the progress of technology, VATS incisions are also decreasing., and the incisional protective sleeve is also being improved to adapt to the operation. For example, 
the incisional protective sleeve with the endoscope fixing device, The protective sleeve with smoke exhaust device, etc. The incision protective sleeve can protect incisions and help to establish operating port(s) and thus has been widely applied in thoracic surgeries. The incision protective sleeve also could be placed into other potential lacuna to establish operation channel, can even create a lacuna in the soft tissue to form operation space (such as the mediastinal operation by subxiphoid approach, etc.). This makes it possible to turn open surgery into minimally invasive surgery (1-5). However, it is common to find senior surgeons, who can skillfully perform difficult surgical operations, having difficulty placing a simple incision protective sleeve, especially for obese patients or those with narrow intercostal spaces from rib deformities. Instead, their assistants can do it simply and instantly. In our current study, we divided the operators into three groups based on their professional titles and the number of video-assisted transthoracic surgeries (VATS) they had performed. The start and end times of protective sleeve insertion were recorded to calculate the average duration of this step in each group. Also, the insertion methods of operators who had completed the insertion within a short period of time were observed, with an attempt to find the insertion methods and skills that are more feasible in clinical settings. It was also found in VATS that, in addition to its conventional applications, the incision protective sleeve can also be used for a number of other functions.

We present the following article in accordance with the MDAR reporting checklist (available at http://dx. doi. org/10. 21037/jtd-20-2703).

\section{Methods}

\section{Clinical data}

Incision protective sleeves were inserted in a total of 1,927 patients (including 1,215 men and 712 women, aged 479 years, with an average age of 45 years) undergoing VATS in our hospital from August 2003 to December 2019. Among them 1,363 patients received 3-port VATS ( 1 camera port and 2 operating ports), 462 received 2-port VATS ( 1 camera port and 1 working port), and 102 received uniportal VATS.

The surgical procedures included VATS lung lobectomy and sleeve resection $(n=416)$, VATS segmentectomy $(n=49)$, VATS wedge resection ( $\mathrm{n}=226$ ), VATS pulmonary bullae resection $(n=490)$, VATS for mediastinal tumors and benign diseases ( $n=318)$, VATS for thoracic trauma $(n=52)$, VATS decortication of pleural fibreboard for empyema $(n=178)$, VATS circular pleural perfusion thermotherapy $(\mathrm{n}=35)$, VATS for benign esophageal diseases $(n=75)$, and others $(n=87)$. Ethics approval by Medical Ethics Committee of Clinical Research and Experiment in Chifeng University Affiliated Hospital (No. fsyy200212). Informed consent obtained from all of study participants. The study conformed to the provisions of the Declaration of Helsinki (as revised in 2013).

\section{Inclusion and exclusion criteria for enrolled patients}

(I) Inclusion criteria: the patients had indications of thoracoscopic surgery and had no contraindications.

(II) Exclusion criteria: the cases which were difficult to perform thoracoscopic surgery and the cases which VATs transferred to thoracotomy.

\section{Surgical methods}

The operators were divided into three groups according to their professional titles: the resident group (residents who had performed fewer than 50 VATS operations), the attending surgeon group (surgeons who had performed 100-200 operations), and the professor group (associate professors or professors who had performed more than 200 operations). In each group, doctors with different surgical experience independently chose one of the four surgical maneuvers, and an incision protective sleeve was placed during the operation. Up to 200 operations were randomly selected from each group, and the chest wall thickness and width of intercostal spaces at the incision site were measured on CT images (Figure 1A,B). The patients' gender, age, incision site, and incision length, the operator's experience, and the time and maneuver of incision protective sleeve placement were recorded.

\section{Maneuvers}

The maneuvers included: (I) guiding the sleeve with the index finger after the opposite side of the sleeve was squeezed flat (Figure $2 A, B$ ), (II) guiding the sleeve with sponge forceps after the opposite side of the sleeve was squeezed flat by the sponge forceps (Figure 2C); (III) guiding the sleeve with sponge forceps after the sleeve was squeezed flat in the shape of a figure 8 (Figure 2D); and (IV) internal traction with sponge forceps (Figure 2E). 

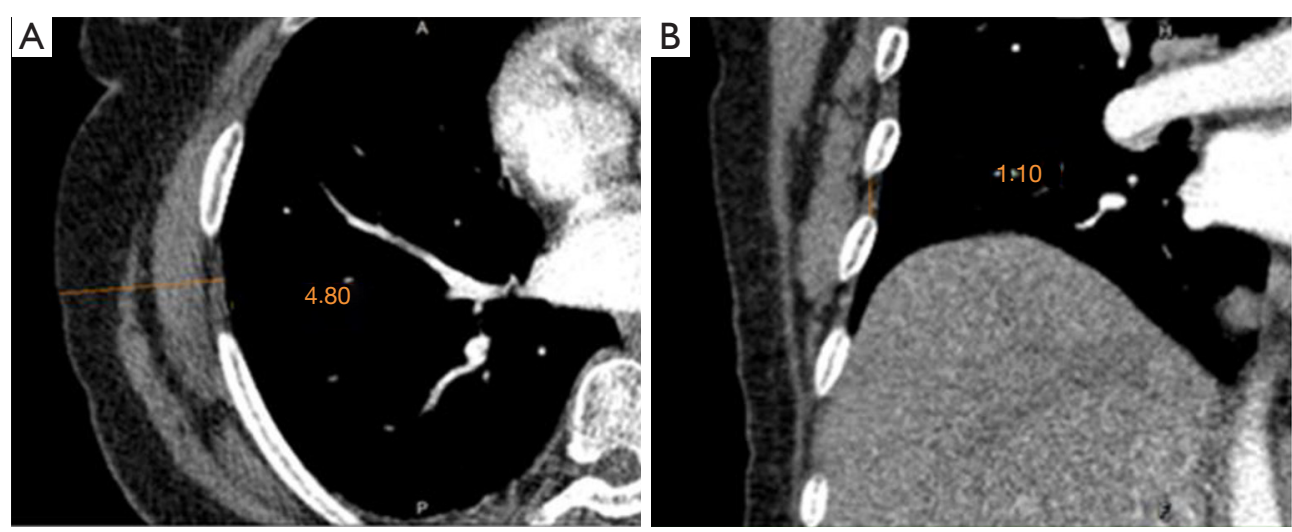

Figure 1 The chest wall thickness and width of intercostal spaces at the incision site measured on CT images. (A) The thickness of the chest wall at the incision site was measured, and the vertical distance from the skin to the parietal pleura was $4.80 \mathrm{~cm}$. (B) The spacing between the ribs at the incision site was measured, and the distance between the lower margin of the upper rib and the upper margin of the lower rib was $1.10 \mathrm{~cm}$.
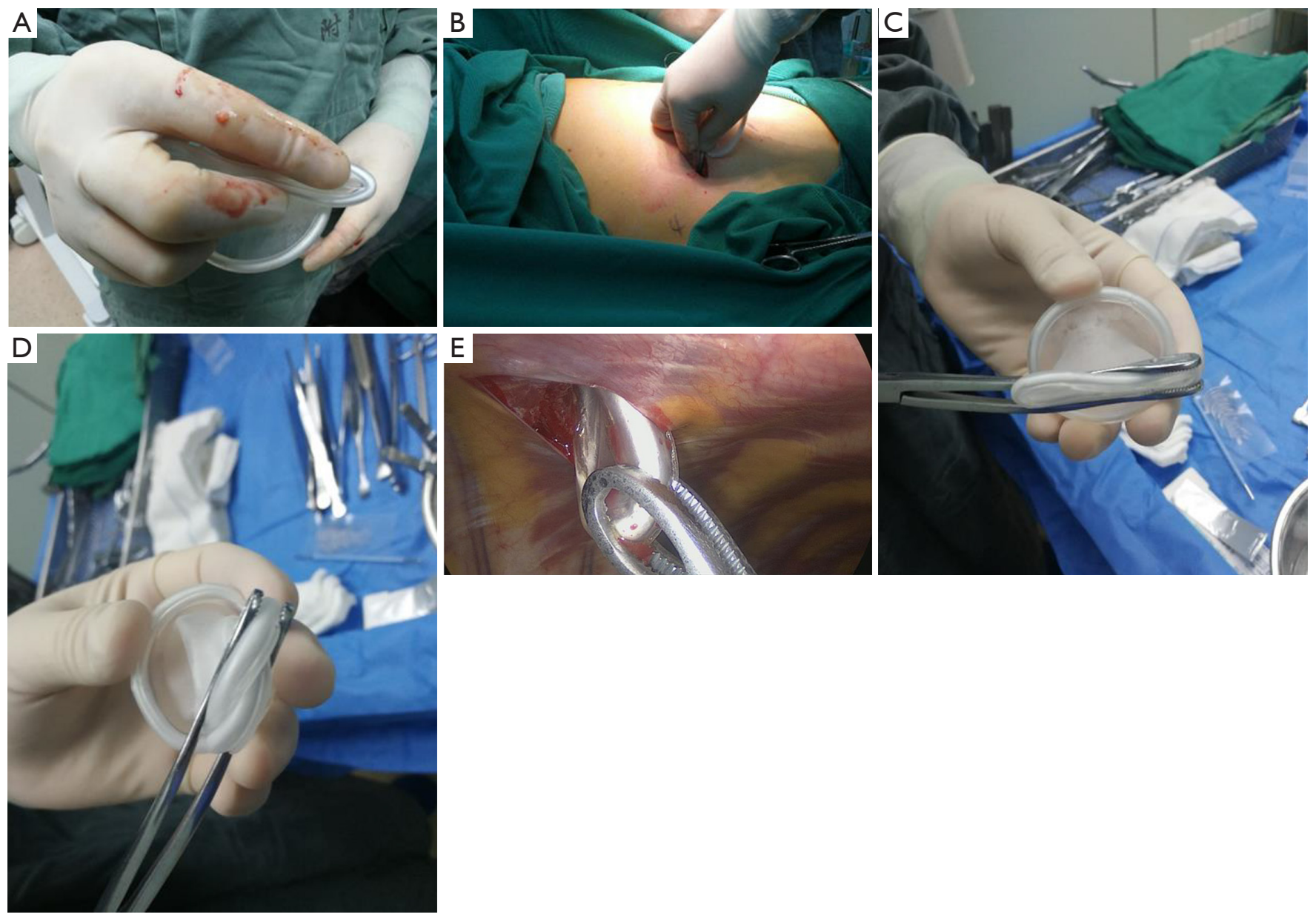

Figure 2 The methods of placing the incision protective sleeves. (A) Squeezed one end of the sleeve flat; (B) placed the sleeve, guiding with the index finger; (C) guiding the sleeve with sponge forceps after the opposite side of the sleeve is squeezed flat by the sponge forceps; (D) guiding the sleeve with sponge forceps after the sleeve is squeezed flat in the shape of a figure 8; (E) internal traction with sponge forceps. 
Table 1 Correlation analysis between the time required for incision protective sleeve placement and various influencing factors

\begin{tabular}{lcc}
\hline \multirow{2}{*}{ Item } & \multicolumn{2}{c}{$\begin{array}{c}\text { Time for incision protective sleeve } \\
\text { placement }\end{array}$} \\
\cline { 2 - 3 } & $r$ & $\mathrm{P}$ value \\
\hline Gender & -0.011 & 0.786 \\
Age & $0.107^{\star \star}$ & 0.009 \\
Operator's group & $-0.707^{\star * *}$ & 0.000 \\
Width of intercostal spaces & $0.115^{\star \star}$ & 0.005 \\
Maneuvers & $0.230^{\star \star *}$ & 0.000 \\
Thickness of chest wall & $0.504^{\star \star *}$ & 0.000 \\
Length of incision & $0.229^{\star \star *}$ & 0.000 \\
\hline
\end{tabular}

${ }^{\star *}, \mathrm{P}<0.01 ;{ }^{* \star \star}, \mathrm{P}<0.001$.

\section{Statistical analysis}

Data were analyzed using SPSS 21.0 software package. Univariate analysis was performed for factors related with the time required for incision protective sleeve placement. Pearson correlation analysis was performed using the time required for incision protective sleeve placement as the independent variable and the patient's gender, age, incision site, chest wall thickness, and width of intercostal spaces at the incision site, the operator's experience, and the length of the incision as the dependent variables. A P value of less than 0.05 was considered statistically significant. The correlation coefficient, denoted as $\mathrm{r}$, represents a positive relationship when it is greater than zero and represents a negative relationship when it is below zero.

Multiple regression linear analysis was performed with the operative time as the dependent variable and with the gender, age, width of intercostal spaces at the incision site, chest wall thickness, incision length, and operator group (set a dummy variable with value 1 as the reference: $Z 1$ : value $2=1$, others $=0 ; Z 2$ : value $3=1$, others $=0$ ), and operator's maneuver (set dummy variable with value 1 as the reference; S1: value $2=1$, others $=0 ; \mathrm{S} 2$ : value $3=1$, others $=0 ; \mathrm{S} 3$ : value $4=1$, others $=0$ ) as the independent variables.

\section{Results}

\section{Correlation analysis showed that (Table 1)}

The results showed that the patients' gender, age, intercostal muscles, chest wall thickness, and incision length, the operator group, and the operator maneuver had significant effects on the operative time $(\mathrm{P}<0.05)$.

In addition to gender, the patient's age, chest wall thickness, and width of intercostal spaces at the incision site, incision length, surgical maneuver, and operator's experience were correlated with the time required for incision protective sleeve placement.

Among these factors, the operator's experience was inversely related to the time required for incision protective sleeve placement, whereas the other factors showed positive correlations.

Among them, the operator's experience, surgical maneuver, chest wall thickness, and length of the incision had significant effects on the time required for the incision protective sleeve placement $(\mathrm{P}<0.0001)$.

\section{As shown in multivariate linear regression analysis (Table 2)}

The patients' gender (not a factor that influenced the time required for incision protective sleeve placement in the correlation analysis), age, width of intercostal spaces, chest wall thickness, and incision length, the operator group, and the operator maneuver had significant effects on the operative time $(\mathrm{P}<0.05)$.

The width of intercostal spaces was negatively correlated with operative time.

Chest wall thickness and incision length were positively correlated with operative time.

The operative time was significantly longer in the resident group than in the attending surgeon group and professor group.

Among the maneuvers, "guiding the sleeve with index finger after the opposite side of the sleeve is squeezed flat" had longer operative time than "guiding the sleeve with sponge forceps after the opposite side of the sleeve is squeezed flat" and "guiding the sleeve with sponge forceps after the sleeve is squeezed flat in the shape of a figure eight" but was shorter than "internal traction with sponge forceps".

\section{Discussion}

Many factors may influence the placement of incision protective sleeve. In our current study, the thickness of chest wall and the width of intercostal spaces at the surgical site were two obvious influencing factors of the time required for incision protective sleeve placement. Some physically strong patients have thick chest muscles, in whom the surgical operation may be more difficult and the time 
Table 2 Multivariate linear regression analysis of factors influencing time required for incision protective sleeve placement

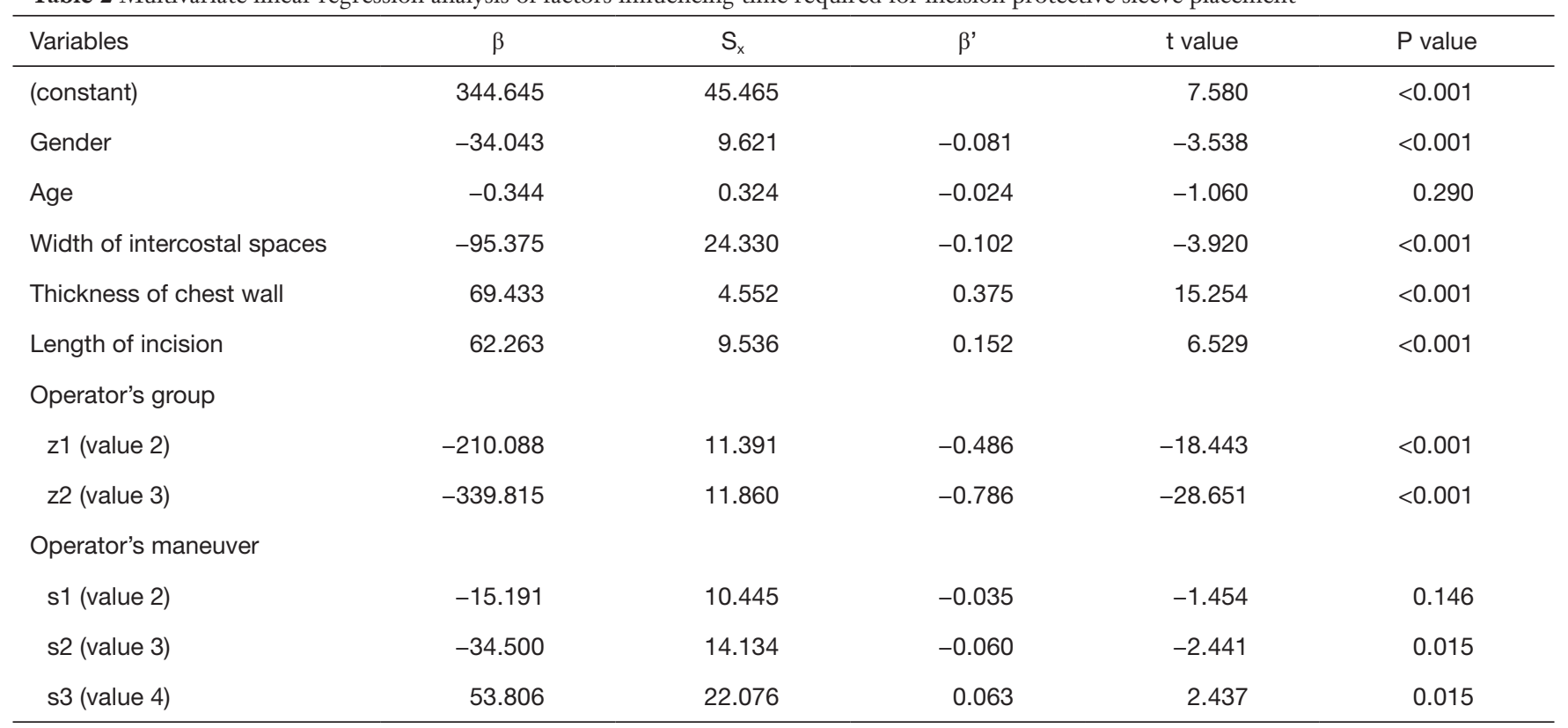

required for incision protective sleeve placement is longer.

On the other hand, thick chest walls are more common in obese and elderly patients, and these patients tend to have thick subcutaneous fat. The chest walls in obese patients can be up to $10 \mathrm{~cm}$ or thicker. Creation of surgical incision in these patients is particularly difficult. Even worse, the leakage of fat during the dissection of the adipose layer will further increase the difficulty of the operation. Experienced surgeons will use their fingers to explore the intercostal space firstly, followed by the blunt separation of the space with hemostatic forceps to facilitate the insertion of incision protective sleeve, which dramatically shortens the time for incision protective sleeve placement.

Incision protective sleeve placement is also difficult in patients with narrow intercostal space as it is difficult for the fingers to pass through the intercostal space; in these patients, instruments such as oval forceps may be used to send one end of the incision protection sleeve into the chest cavity. Of course, these are many other challenging situations. Most patients with intercostal stenosis often also have severe pleural diseases such as chest wall deformity, empyema-induced fibrous peel formation, and dense pleural adhesions, which are also factors that cause the prolonged placement of incision protective sleeve. In addition, surgical devices may injure adjacent lung tissues when they enter the chest cavity.

Different maneuvers also have significant impacts on the placement of the incision protective sleeve. The placement of the incision protective sleeve is a skill-demanding step that requires repeated training to master, especially for patients with thick chest wall muscles and fat. According to our experience, 4 maneuvers including guiding the sleeve with the index finger after the opposite side of the sleeve is squeezed flat, guiding the sleeve with the sponge forceps after the opposite side of the sleeve is squeezed flat by the sponge forceps, guiding the sleeve with sponge forceps after the sleeve is squeezed flat in the shape of a figure 8 , and internal traction with sponge forceps, are efficient and rapid methods that can remarkably shorten the surgical time. For patients with thick chest walls and narrow intercostal spaces, clamping with oval forceps is more convenient for the placement of incision protective sleeve. For patients with a particularly narrow incision, "internal traction with sponge forceps" will be more convenient and faster.

In our opinion, in addition to protecting the incision and creating the operation channel, the incision protective sleeve has many other useful functions (6-19):

(I) As a means to raise the perfusion level (Figure $3 A$ ): during conventional VATS coelom continued circulatory hyperthermia perfusion, the perfusion fluid will overflow out of the body via the operating port as the level of the perfusion fluid rises. As a result, the perfusion fluid cannot fill the thoracic cavity, thereby reducing the 

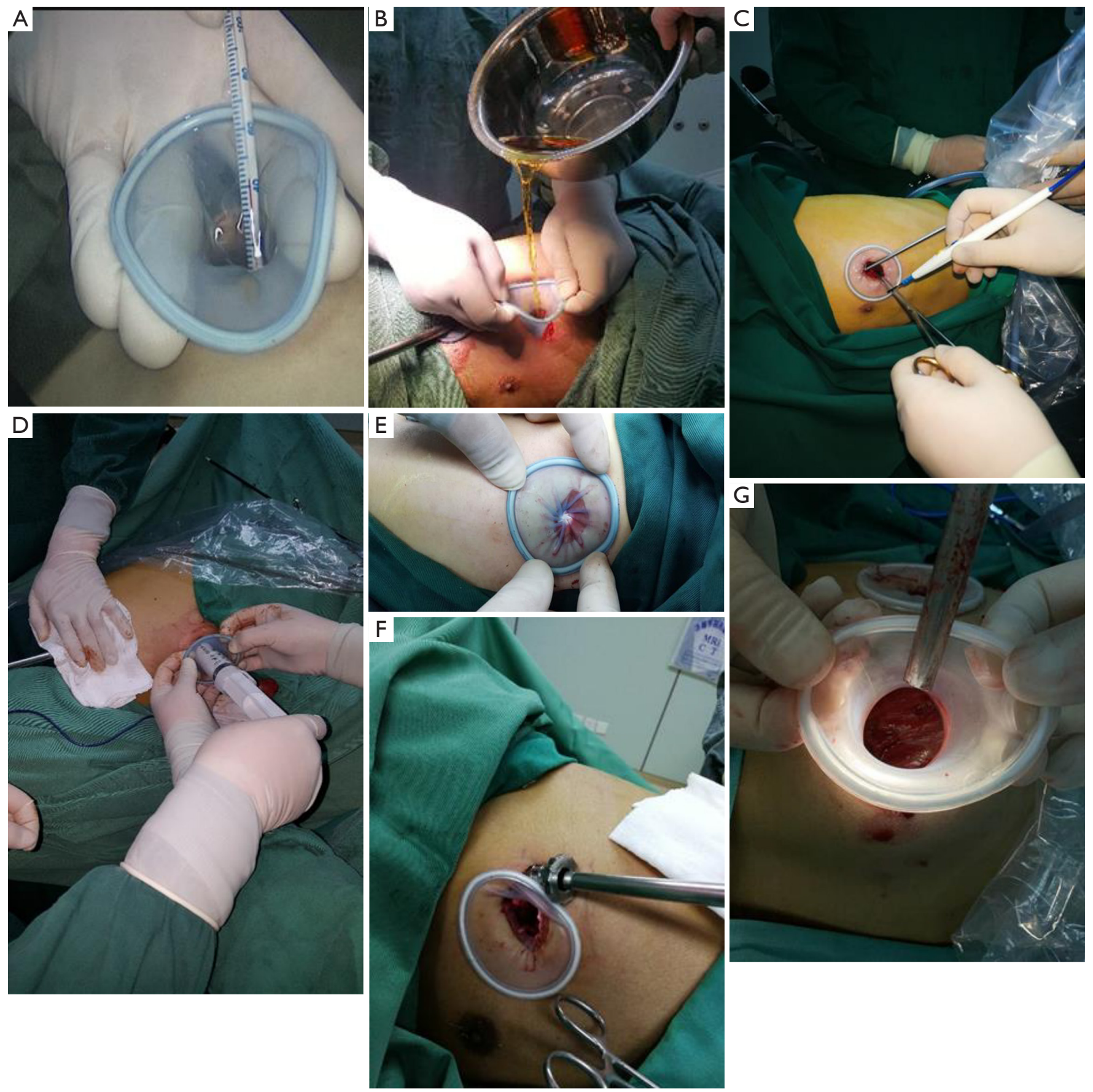

Figure 3 Other founctions of incision protective sleeves. (A) To raise the perfusion level; (B) as a funnel that simplifies water injection; (C) as an electrical insulation tunnel for conventional surgical instruments; (D) as a simple device for powder-spraying and closing during pleura fixation; (E) as a temporary chest sealer; (F) as a fulcrum for the camera port during uniportal VATS. VATS, video-assisted thoracoscopic surgery; $(\mathrm{G})$ for establishing a surgical tunnel during minimally invasive surgery on the chest wall. 
effectiveness of hyperthermic perfusion; in addition, chemotherapy drugs may enter the subcutaneous tissues under the pressure of the perfusion machine and thus cause tissue necrosis. As a remedy, the perfusion level can be raised by the stretching effect of the incision protective sleeve, which enables the perfusion fluid to fill the thoracic cavity and improves the quality of perfusion; also, it can prevent chemotherapy drugs from entering the subcutaneous tissue.

(II) As a funnel that simplifies water injection (Figure 3B): during VATS, water injection via the operating port is often required for rinsing. This maneuver is inconvenient due to the narrow and limited space of the port. In such cases, the incision protective sleeve can be stretched into a funnel shape to facilitate the pouring of water into the thoracic cavity.

(III) As an electrical insulation tunnel for conventional surgical instruments (Figure 3C): as an insulating device, the incision protective sleeve can facilitate electrocoagulation for hemostasis with some conventional and extended metal instruments.

(IV) As a simple device for powder-spraying and closing during pleura fixation (Figure 3D): during VATS for pleural fixation, talcum powder and erythromycin powder are often sprayed into the pleural cavity, during which the incision protective sleeve can be stretched into a funnel shape and perfectly fit with a $50-\mathrm{ml}$ syringe containing such powder, allowing the quick spraying of the powder into the thoracic cavity.

(V) As a temporary chest sealer (Figure 3E): rotating the protective sleeve to tighten it can temporarily close the thoracic cavity, so as to prevent the spilling of powder or liquid; otherwise such powder or liquid may be absorbed into the airways of medical staff, contaminate surgical gowns and other protective clothing, or even cause iatrogenic events.

(VI) As a fulcrum for the camera port during uniportal VATS (Figure 3F): to reduce the occupied space in the working port during uniportal VATS, a trocar may be placed into the thoracic cavity from the edge of the protective sleeve, whose elasticity can be used as a fulcrum to adjust the illumination in the thoracic cavity; meanwhile, the trocar also helps to reduce the fatigue and trembling of the assistant's arm after hanging for a long time.

(VII) For establishing surgical tunnel during minimally invasive surgery on chest wall (Figure $3 G$ ): after the protective sleeve is placed in the gap between the chest muscles and ribs, pulling it can create a potential tunnel. A multipoint placement can establish a potential operating plane that facilitates a variety of VATS procedures for rib fractures and chest wall tumors.

(VIII) As a compression tool for stopping incision bleeding: Bleeding at the operating port is quite challenging for most operators. Electrocoagulation for stopping bleeding is timeconsuming. In fact, mild hemorrhage can be stopped by utilizing the retractive tension of the protective sleeve.

\section{Limitations}

This research is related to the problems found in doctors' daily work, and analysed and summarized based on the previous research experience. Therefore, this paper has certain limitations.

Firstly, all the data are single-center data, which is not universal enough. If the data is multi-center, the results will be more representative.

In this paper, because there is no better evaluation method for the effect of incisional protective sleeve placement, only the operation time is used as the evaluation standard, which is a little simple.

In addition, as far as possible, we included the informations such as chest wall condition, surgical experience, operation effect and surgical experience in the data. However, the related factors of the placement effect of the incisional protective sleeve are still more than this. If the support conditions are adequate, the results would be more reliable.

Due to limited conditions, we only studied the most common incisional protective sleeve. With the continuous improvement of surgical techniques, the incision protective cover, as one of the surgical instruments, will also change accordingly. Then its use and operation skill will also change accordingly.

\section{Acknowledgments}

Funding: None. 


\section{Footnote}

Reporting Checklist: The authors have completed the MDAR reporting checklist. Available at http://dx. doi. org/10. 21037/jtd-20-2703

Data Sharing Statement: Available at http://dx. doi. org/10. 21037/jtd-20-2703

Conflicts of Interest: All authors have completed the ICMJE uniform disclosure form (available at http://dx. doi. org/10. 21037/jtd-20-2703). The authors have no conflicts of interest to declare.

Ethical Statement: The authors are accountable for all aspects of the work in ensuring that questions related to the accuracy or integrity of any part of the work are appropriately investigated and resolved. Ethics approval by Medical Ethics Committee of Clinical Research and Experiment in Chifeng University Affiliated Hospital (No. fsyy200212). Informed consent obtained from all of study participants. The study conformed to the provisions of the Declaration of Helsinki (as revised in 2013).

Open Access Statement: This is an Open Access article distributed in accordance with the Creative Commons Attribution-NonCommercial-NoDerivs 4.0 International License (CC BY-NC-ND 4.0), which permits the noncommercial replication and distribution of the article with the strict proviso that no changes or edits are made and the original work is properly cited (including links to both the formal publication through the relevant DOI and the license). See: https://creativecommons.org/licenses/by-ncnd/4.0\%.

\section{References}

1. Su Z, Bai Y, Zhang Y, et al. Video-assisted thoracic surgery resection of rib osteophytes. J Thorac Dis 2015;7:490-493.

2. Nakanishi R, Yamashita T, Oka S. Initial experience of video-assisted thoracic surgery lobectomy with partial removal of the pulmonary artery. Interact Cardiovasc Thorac Surg 2008;7:996-1000.

3. Shaw JP, Dembitzer FR, Wisnivesky JP, et al. Videoassisted thoracoscopic lobectomy: state of the art future directions. Ann Thorac Surg 2008;85:S705-9.
4. O'Sullivan KE, Kreaden US, Hebert AE, et al. A systematic review of robotic versus open and video assisted thoracoscopic surgery (VATS) approaches for thymectomy. Ann Cardiothorac Surg 2019;8:174-93.

5. Ye GL, Yang J, Gu WQ, et al. The application of incision protection sleeve in video-assisted thoracoscopic extended thymectomy. J Clin Exp Med 2012;11:945-7.

6. Su ZY, Zhang YL, Jiang TS, et al. Removal of neurogenic tumors at thoracic outlet under total thoracoscope: Report of Two Cases. Chin J Thorac Cardiovasc Surg 2011;27:635.

7. Su ZY, Jiang TS, Zhang YL, et al. Guiding significance of rib fractures in surgical operations. Chin J Thorac Cardiovasc Surg 2014;30:415-6.

8. Su ZY, Ding L, Li JW, et al. Ectopic thyroid gland: Report of one case. Chin J Thorac Cardiovasc Surg 2018;34:314-5.

9. Su ZY, Zhang YL, Jiang TS, et al. Suturing technique for severe lung laceration with lung lobes preserved. Chin J Thorac Cardiovasc Surg 2010;26:415-7.

10. Su ZY, Zhang YL, Su BH, et al. Indications and key techniques of internal fixation of rib fractures in videoassisted thoracoscopic surgery. Chin J Thorac Cardiovasc Surg 2015;31:561.

11. Su ZY, Zhang YL, Su BH, et al. Weaving and traction technology for fractured ribs in video-assisted thoracoscopic surgery. Chin J Thorac Cardiovasc Surg 2015;8:25-7.

12. Su ZY, Zhang YL, Jiang TS, et al. The role of videoassisted thoracoscopic surgery in fast track surgery. Chin J Thorac Cardiovasc Surg 2010;3:52-4.

13. Su ZY, Zhang YL, Jiang TS, et al. Techniques of bleeding control in video-assisted thoracoscopic surgery. Chin J Thorac Cardiovasc Surg 2013;20:244.

14. Su ZY, Zhang YL, Jiang TS, et al. Influencing factors on the quality of the circular pleural perfusion thermotherapy under video-assisted thoracoscopy. Chin J Thorac Cardiovasc Surg 2017;20:902-4.

15. Su ZY, Zhang YL, Jiang TS, et al. Discuss the indications of severe chest wall fractures by using a kind of absorbable screws named poly-L-lactic acid screws. Chin J Thorac Cardiovasc Surg 2010;17423-45.

16. Su Z. Critical chest trauma treatment technology. People's Military Medical Press, 2014:84-92.

17. Su ZY, Zhang YL, Su BH, et al. Choice of surgical pathway and incision for multiple fractured ribs. Chin J Thorac Cardiovasc Surg 2016;23:89-91. 
18. Su ZY. Thoracic trauma therapeutics. Beijing: Science Press, 2018:232-62.

19. Su ZY, Zhang YL, Wei F, et al. Su's total thoracoscopic

Cite this article as: $\mathrm{Su} \mathrm{Z}, \mathrm{Wu} \mathrm{C}$, Bian $\mathrm{H}$, Zhou Z, Jiang T, Zhao X, Liu F, Zhang Y, Lin K, Gao Q. Utilities and placement skills of the incision protective sleeve in video-assisted thoracoscopic surgery (VATS). J Thorac Dis 2020;12(12):72727280. doi: $10.21037 /$ jtd-20-2703 implantation and fixation of bone plate and bone nail in thoracic cavity for rib fractures. Chin J Thorac Cardiovasc Surg 2013;20:362-4. 